\title{
Glaesserella parasuis serotype 4 HPS4-YC disrupts the integrity of the swine tracheal epithelial barrier and facilitates bacterial translocation
}

\author{
Qing Wang ${ }^{1}$, Xiaojing Chang ${ }^{2}$, Mingxing Liư ${ }^{2}$, Qi Lu' ${ }^{1}$, Meng Zhu' ${ }^{1}$ Huixing Lin ${ }^{2}$ and Hongjie Fan ${ }^{2,3^{*}}$ (D)
}

\begin{abstract}
Glaesserella parasuis (G. parasuis) is a commensal bacterium in the upper respiratory tract of pigs that can also cause the swine Glässer disease, which induces an intensive inflammatory response and results in significant economic losses to the swine industry worldwide. G. parasuis can cause disease through infection of the respiratory tract, resulting in systemic infection, but the mechanism is largely unknown. Recently we showed that Glaesserella parasuis serotype 4 (GPS4) increased swine tracheal epithelial barrier permeability, resulting in easier bacterial translocation. Tight junction proteins (TJ) play a crucial role in maintaining the integrity and impermeability of the epithelial barrier. GPS4 decreased the expression of the TJ ZO-1 and occludin in swine tracheal epithelial cells (STEC). Furthermore, the proinflammatory cytokines IL-6, IL-8 and TNF-a were significantly upregulated in GPS4-infected STEC, and both the MAPK and NF-KB signaling pathways were activated and contributed to the expression of TNF-a. We demonstrate that the production of proinflammatory cytokines, especially TNF-a, during GPS4 infection was involved in barrier dysfunction. Additionally, animal challenge experiments confirmed that GPS4 infection downregulated TJ in the lungs of piglets and induced a severe inflammatory response. In general, G. parasuis infection downregulated the expression of TJ and induced massive secretion of proinflammatory cytokines, resulting in epithelial barrier disruption and favoring bacterial infection. This study allowed us to better understand the mechanism by which G. parasuis crosses the respiratory tract of pigs.
\end{abstract}

Keywords: Glaesserella parasuis, swine tracheal epithelial cells, tight junction proteins, proinflammatory cytokines

\section{Introduction}

Glaesserella parasuis (G. parasuis), the causative agent of Glässer disease, is a Gram-negative opportunistic bacterial pathogen that colonizes the upper respiratory tract of pigs. G. parasuis infection induces severe systemic inflammatory reactions characterized by fibrinous polyserositis, pneumonia, arthritis and meningitis, resulting

\footnotetext{
*Correspondence: fhj@njau.edu.cn

${ }^{2}$ MOE Joint International Research Laboratory of Animal Health and Food Safety, College of Veterinary Medicine, Nanjing Agricultural University, Nanjing 210095, China

Full list of author information is available at the end of the article
}

in extensive economic losses for the pig industry $[1,2]$. To date, 15 serotypes of G. parasuis have been defined, in addition to nontypeable isolates. Serotypes 4 and 5 are the most prevalent serovar isolates from pigs with clinical signs of Glässer disease in China [3]. Secondary or concurrent G. parasuis infection with other pathogens such as porcine reproductive and respiratory syndrome virus (PRRSV) or swine influenza virus, remains an epidemic, leading to increased morbidity and mortality, and resulting in more severe challenges to the control of G. parasuis infection $[4,5]$. original author(s) and the source, provide a link to the Creative Commons licence, and indicate if changes were made. The images or other third party material in this article are included in the article's Creative Commons licence, unless indicated otherwise in a credit line to the material. If material is not included in the article's Creative Commons licence and your intended use is not permitted by statutory regulation or exceeds the permitted use, you will need to obtain permission directly from the copyright holder. To view a copy of this licence, visit http://creativecommons.org/licenses/by/4.0/. The Creative Commons Public Domain Dedication waiver (http://creativeco mmons.org/publicdomain/zero/1.0/) applies to the data made available in this article, unless otherwise stated in a credit line to the data. 
As a pathogen that can cause infection through the respiratory tract, $G$. parasuis has to break through the respiratory epithelial barrier to enter the bloodstream and induce systemic infection. The respiratory epithelium is an important barrier to defend against harmful particles and inhaled pathogens, and barrier failure of the respiratory epithelium contributes to the pathogen invasions [6,7]. The epithelial barrier is mainly composed of the apical junctional complex, composed of tight junctions, adhesion junctions and desmosomes $[8,9]$. Tight junction proteins (TJ), including $\mathrm{ZO}-1$, occludin and claudins, play a major role in maintaining the barrier function of epithelial cells [7]. Some studies have demonstrated that respiratory pathogens can disrupt epithelial TJ and damage barrier function [10, 11]. For example, Streptococcus pneumoniae and Haemophilus influenzae infection cause downregulation of $\mathrm{TJ}$ in human airway epithelial cells and induce disruption of epithelial barrier integrity [11]. Additionally, Mycoplasma hyopneumoniae reduces ZO-1 expression and disrupts the integrity of the porcine airway epithelial barrier [12]. However, there are few studies on the effects of G. parasuis on TJ expression and respiratory epithelial barrier integrity $[13,14]$. The aim of the study is to investigate how G. parasuis disrupts the respiratory epithelial barrier to cause systemic infection.

Numerous studies have reported that excessive proinflammatory cytokine production can damage the integrity of the epithelial barrier [15]. Petecchia et al. reported that exposure to the cytokines TNF- $\alpha$, IL-4 and IFN- $\gamma$ significantly reduced the expression of the TJ ZO-1 and occludin, damaging the human airway epithelial barrier [16]. In addition, TNF- $\alpha$ secreted by pig tracheal epithelial cells damage $\mathrm{TJ}$ and disrupt the epithelial barrier; TNF- $\alpha$ can also promote IL- 6 and IL-8 secretion in epithelial cells [13]. Previous studies have shown that $G$. parasuis infection evokes a strong inflammatory response in the host, and the excessive release of cytokines can cause lung damage [17]. However, whether this excessive inflammatory response may have a destructive effect on the integrity of the epithelial barrier is still unclear.

In this study, swine tracheal epithelial cells (STEC) were used to explore the effects of G. parasuis on the expression of $\mathrm{TJ}$ and permeability of the tracheal epithelial barrier. The production of proinflammatory cytokines and related signaling pathways were further evaluated. The effects of secreted cytokines on the permeability of the epithelial barrier were assessed. In addition, G. parasuis-induced disruption of $\mathrm{TJ}$ and a severe inflammatory response were verified through piglet challenge experiments.

\section{Materials and methods}

\section{Bacterial strain and cell line}

The GPS4 strain used in this study, HPS4-YC, was isolated from a diseased pig in Jiangsu, China, in 2016. Bacteria were cultured in trypticase soy broth (TSB, BD, USA) or on trypticase soy agar (TSA) supplemented with $5 \%(\mathrm{v} / \mathrm{v})$ fetal bovine serum (FBS, Gibco, USA) and $50 \mu \mathrm{g} /$ $\mathrm{mL}$ nicotinamide adenine dinucleotide (NAD, Biosharp, China).

Immortalized swine tracheal epithelial cells (STEC) were cultured in Dulbecco modified Eagle medium (DMEM, Gibco, USA) supplemented with $10 \%(\mathrm{v} / \mathrm{v})$ FBS (Gibco, USA) at $37{ }^{\circ} \mathrm{C}$ and $5 \% \mathrm{CO}_{2}$. Subsequently, cells were digested with trypsin, suspended in culture medium, distributed into cell culture plates, and incubated until the cells were confluent.

\section{Giemsa staining}

STEC were cultured on sterile glass slides until completely confluent. GPS4 strain HPS4-YC was grown in supplemented TSB overnight at $37^{\circ} \mathrm{C}$ and $180 \mathrm{rpm}$. Bacteria were harvested by centrifugation at $5000 \times g$ for $5 \mathrm{~min}$, washed three times with phosphate buffered saline (PBS) and resuspended in DMEM without FBS. Cells were infected with HPS4-YC with different multiplicity of infection (MOI) values of 10, 100 or 1000 . Three parallel samples were set for each group. After incubation for $2 \mathrm{~h}$ at $37^{\circ} \mathrm{C}$ and $5 \% \mathrm{CO}_{2}$, the cells were washed three times with PBS and fixed with $4 \%$ paraformaldehyde for $30 \mathrm{~min}$. The slides were then dyed with Giemsa staining solution (Beyotime, China). After washing away the dye solution, the slides were dried and observed under an optical microscope.

\section{Adherence and invasion assays}

STEC were distributed into 24-well plates and incubated at $37{ }^{\circ} \mathrm{C}$ in $5 \% \mathrm{CO}_{2}$ until the cells were confluent. Cells were then inoculated with HPS4-YC at different MOI of 10,100 or 1000 . Plates were centrifuged at $800 \times g$ for $10 \mathrm{~min}$. After $2 \mathrm{~h}$ of incubation at $37{ }^{\circ} \mathrm{C}$ with $5 \% \mathrm{CO}_{2}$, cells were washed three times with PBS to remove nonadherent bacteria. For the adhesion assay, the cells were lysed with double-distilled water and diluted appropriately with PBS. The number of adherent bacteria was determined by spreading on supplemented TSA. For the invasion assay, extracellular bacteria were killed by the addition of DMEM containing $100 \mu \mathrm{g} / \mathrm{mL}$ gentamicin (Solarbio, China) and $5 \mu \mathrm{g} / \mathrm{mL}$ penicillin G (Solarbio, China) for an additional $1 \mathrm{~h}$. Antibiotic-treated cells were washed three times in PBS, lysed with double-distilled water, and diluted appropriately with PBS before 
spreading on supplemented TSA to determine bacterial counts. Assays were performed in triplicate and repeated three times.

\section{Measurement of cell viability}

An Enhanced Cell Counting Kit-8 (CCK-8, Beyotime, China) was used to assess the viability of STEC following the manufacturer's protocols. Briefly, STEC were seeded at $2.0 \times 10^{3}$ cells/well in 96-well plates and then infected with HPS4-YC at different MOI of 10, 100 or 1000 for 6,12 and $24 \mathrm{~h}$. After incubation for the designated time, $10 \%(\mathrm{v} / \mathrm{v})$ CCK- 8 solution was added and incubated at $37^{\circ} \mathrm{C}$ for $1 \mathrm{~h}$ in darkness. Wells without cells were assayed as background. Absorbance at $450 \mathrm{~nm}$ was detected using an enzyme-linked immunosorbent assay reader. Assays were performed with four replicates and repeated as three independent experiments.

\section{Determination of epithelial barrier integrity}

According to our previous study, an in vitro tracheal epithelial barrier model was constructed with STEC using polytetrafluoroethylene $3 \mu \mathrm{M}$ pore-size membrane transwells (Corning, USA) [18]. Transwells containing STEC were uninfected or infected with HPS4-YC (MOI 100) for 4, 6, 8, 12, 18 and $24 \mathrm{~h}$. The transepithelial electrical resistance (TEER) was measured with a Millicell ERS-2 electrical resistance system (Millipore, USA). Moreover, FITC-conjugated dextran 4000 (Sigma, USA) was used to measure the paracellular permeability of the tracheal epithelial barrier infected with HPS4-YC for 6, 12, 18 and $24 \mathrm{~h}$. After experimental treatment, the media in the upper and lower chambers were removed; the basolateral medium was replaced with fresh DMEM, and then DMEM containing $1 \mathrm{mg} / \mathrm{mL} 4 \mathrm{kDa}$ FITC-conjugated dextran was added to the apical chamber of the inserts. One hour later, $100 \mu \mathrm{L}$ of sample media from the basolateral chambers was collected and tracer concentrations were quantified by Tecan Infinite 200 PRO (Tecan, Switzerland). Additionally, STEC were uninfected or infected with HPS4-YC for $24 \mathrm{~h}$, and the supernatant was harvested and filtered with a $0.22 \mu \mathrm{m}$ filter to remove suspended bacteria before being added to the upper chambers for another $12 \mathrm{~h}$ or $24 \mathrm{~h}$. Additionally, recombinant human TNF- $\alpha$ (Cell Signaling Technology, USA) was added to the upper chambers at concentrations of $0.1,1$, or $10 \mathrm{ng} / \mathrm{mL}$ and incubated for $24 \mathrm{~h}$. TEER and FITC-dextran were measured as described above. All assays were performed in triplicate and repeated three times.

\section{HPS4-YC translocation assay}

Experiments were performed when an in vitro tracheal epithelial barrier model was constructed. Transwells containing STEC were infected with HPS4-YC at an MOI of 100 for $4,6,8,10,12$, and $14 \mathrm{~h}$. The medium in the basolateral chamber of the transwells was collected and spread on supplemented TSA plates to count bacterial colonies. Assays were performed with four replicates and repeated as three independent experiments.

\section{Western blotting}

STEC grown in 24-well plates were infected with HPS4$\mathrm{YC}$ at an MOI of 100 for the designated time. Cells were lysed in RIPA buffer (Proteintech, China) and centrifuged, and the supernatant was collected. The lysate proteins were boiled with $5 \times$ SDS-PAGE Sample Loading Buffer (KeyGEN Biotech, Nanjing, China) for $10 \mathrm{~min}$. Then, the proteins were separated on a gel by SDS-PAGE and transferred to a $0.22 \mu \mathrm{m}$ polyvinylidene fluoride (PVDF) membrane. Membranes were blocked in 5\% skimmed milk for $2 \mathrm{~h}$ at $37^{\circ} \mathrm{C}$ and incubated with specific primary antibodies at $4{ }^{\circ} \mathrm{C}$ overnight. Then, membranes were incubated with HRP-goat anti-mouse IgG H\&L (1:5000, Proteintech, China) or HRP-goat anti-rabbit IgG H\&L (1:5000, Proteintech, China) for $1 \mathrm{~h}$ at $37^{\circ} \mathrm{C}$. Protein bands were incubated with an ECL chemiluminescence detection kit (Vazyme, China) and visualized using a chemiluminescence image analysis system (Tanon, China). The protein band intensities were quantified by ImageJ software, and $\beta$-actin was used as a control. The primary antibodies used were as follows: anti-ZO-1 mouse mAb (1:500, Invitrogen, USA), anti-occludin mouse mAb (1:1000, Invitrogen, USA), anti-phospho-p38 rabbit mAb, anti-p38 rabbit $\mathrm{mAb}$, anti-phospho-ERK rabbit $\mathrm{mAb}$, anti-ERK rabbit $\mathrm{mAb}$, anti-phospho-JNK rabbit $\mathrm{mAb}$, anti-JNK rabbit $\mathrm{mAb}$, anti-phospho-NF- $\mathrm{kB}$ p65 rabbit $\mathrm{mAb}$, antiNF-кB p65 rabbit mAb, anti-phospho-ІкB $\alpha$ rabbit mAb, anti-IкB $\alpha$ rabbit $m A b(1: 1000$, Cell Signaling Technology, USA), and anti- $\beta$-actin mouse mAb (1:5000, Proteintech, China).

\section{Quantitative reverse transcription PCR (qRT-PCR) assays} Total RNA was extracted from STEC using TRIzol reagent (TaKaRa, Japan). cDNA was synthesized using HiScript Q RT SuperMix for qPCR (+gDNA wiper) (Vazyme, China). qRT-PCR were performed according to the instructions of ChamQ Universal SYBR qPCR Master Mix (Vazyme, China) on the ABI StepOne Real-Time PCR System (Applied Biosystems, USA). The GAPDH gene was used as an internal control. All primers are shown in Table 1, and relative quantification compared to the uninfected cells was calculated based on the $2^{-}$ $\Delta \Delta \mathrm{Ct}$ method [19]. All qRT-PCR tests were performed in triplicate. 
Table 1 qRT-PCR primers

\begin{tabular}{lll}
\hline Gene & Forward & Reverse \\
\hline ZO-1 & GGGTGTTGAGCTCCATAGAAA & GTCTCGGCAGACCTTGAAATA \\
occludin & CGGATTCTGTCTATGCTCGTTAT & TAGCCCATACCACCTCCTATT \\
IL-6 & GGAGACCTGCTTGATGAGAATC & CAGCCTCGACATTTCCCTTAT \\
IL-8 & TTCTGCAGCTCTCTGTGAGGC & GGTGGAAAGGTGTGGATGC \\
TNF-a & CCTACTGCACTTCGAGGTTATC & ACGGGCTTATCTGAGGTTTG \\
GAPDH & GATGCTGGTGCTGAGTATGT & GGCAGAGATGATGACCCTTT \\
\hline
\end{tabular}

Immunofluorescent staining of ZO-1 and occludin

STEC were uninfected or infected with HPS4-YC for $12 \mathrm{~h}$ or $24 \mathrm{~h}$, then cells were fixed with $4 \%$ paraformaldehyde (Beyotime, China) for $15 \mathrm{~min}$. After being blocked with $1 \% \mathrm{BSA}$ at $37{ }^{\circ} \mathrm{C}$ for $1 \mathrm{~h}$, samples were incubated with primary antibodies against ZO-1 $(5 \mu \mathrm{g} / \mathrm{mL}$, Invitrogen, USA) and occludin (5 $\mu \mathrm{g} / \mathrm{mL}$, Invitrogen, USA) at $4{ }^{\circ} \mathrm{C}$ overnight. Then, the samples were incubated in FITC goat anti-mouse IgG (1:200, Abbkine, China) at $37{ }^{\circ} \mathrm{C}$ for $1 \mathrm{~h}$ in the dark. Finally, nuclei were stained with DAPI (Beyotime, China). All the specimens were examined using a Zeiss laser scanning microscope (Carl Zeiss, Germany). Assays were repeated as three independent experiments.

\section{Inhibition assay}

To explore the roles of mitogen-activated protein kinases (MAPK) and nuclear factor-kappa B (NF-kB) signaling pathways in cytokine production, STEC were pretreated with different inhibitors for $1 \mathrm{~h}$. The infection time of HPS4-YC was $12 \mathrm{~h}$. The inhibitors used were as follows: SB203580 (p38 inhibitor, MCE, USA), U0126 (ERK inhibitor, MCE, USA), SP600125 (JNK inhibitor, MCE, USA), and BAY11-7082 (NF-kB inhibitor). The concentration of inhibitor used was $10 \mu \mathrm{M}$, based on a previously published reference [20]. STEC treated with equal volumes of DMSO served as controls.

\section{Animal challenge experiments}

Five three-week-old female piglets were selected from a healthy herd. All piglets were confirmed to be seronegative for PCV2, PRRSV, G. parasuis, Streptococcus suis serotype 2 and Actinobacillus pleuropneumoniae. One week later, piglets were randomly divided into two groups: the HPS4-YC-infected group $(n=3)$ and the control group $(n=2)$. Piglets in the HPS4-YC-infected group were challenged intranasally $(1 \mathrm{~mL})$ and intraperitoneally $(2 \mathrm{~mL})$ with HPS4-YC $\left(4.0 \times 10^{9} \mathrm{CFU} / \mathrm{mL}\right)$ on the same day. The infection methods and doses were determined from previously published references[17, 21]. Blood samples were taken at 3, 5 and 7 days post-inoculation (dpi) with HPS4-YC for serum isolation. Piglets were necropsied at $7 \mathrm{dpi}$, and lung samples were collected for further analysis. The animal experiments were approved by the Ethical Committee for Animal Experiments of the Nanjing Agricultural University (NJAU. No20210510064) and were in accordance with the guidelines of the Animal Welfare Council of China.

Total protein and RNA were extracted from equal amounts of lung tissues from different areas of the lungs according to the instructions of the Whole Cell Lysis Assay (Solarbio, China) and Total RNA Kit I (OMEGA, USA). Western blotting and qRT-PCR assays were performed to evaluate the expression of ZO-1 and occludin. Levels of cytokines IL- 6 , IL- 8 and TNF- $\alpha$ in the serum samples or culture supernatant of STEC were assessed using commercial ELISA kits (Fankew, China). Hematoxylin and eosin (H\&E) staining of the lungs and immunofluorescence staining for $\mathrm{ZO}-1$ and occludin were completed by Wuhan Servicebio Technology Co., Ltd.

\section{Statistical analysis}

The results in the study were recorded as the mean \pm standard deviation (SD) and analyzed and graphed using GraphPad Prism 8. Statistical differences were assessed using Student $t$ test and one-way analysis of variance (ANOVA) with Tukey test. A value of $P<0.05$ was considered significant.

\section{Results}

\section{Infection of HPS4-YC in STEC}

To establish an in vitro GPS4-infected cell model, the susceptibility of STEC infected by HPS4-YC was evaluated. Giemsa staining results show that HPS4-YC had a potential to infect STEC, and that the number of bacteria observed increased with increasing MOI (Figure 1A). To quantify the number of HPS4-YC adherent and invading STEC, adherence and invasion assays were performed. As shown in Figures 1B, C, when the MOI of HPS4-YC was 1000 , the adherent and invasive bacteria were significantly higher $(p<0.001)$ than that at an MOI of 100 , when the MOI of HPS4-YC was 100, the adherent and invasive bacteria were significantly higher $(p<0.001)$ than that at an MOI of 10 , with the number of bacteria that adhered and invaded STEC being dose-dependent; this result was consistent with the results of Giemsa staining.

Additionally, cell viability was evaluated to determine the optimal MOI of HPS4-YC in vitro. The results show that there was no significant cytotoxicity to infected cells when the MOI of HPS4-YC were 10 and 100 within $24 \mathrm{~h}$. However, when the MOI increased to 1000, the cell viability was significantly decreased at $12 \mathrm{~h}$ and $24 \mathrm{~h}$ $(p<0.001)$ compared with the control group (Figure 1D). Therefore, an MOI of 100 was selected as the most appropriate MOI in subsequent experiments. 

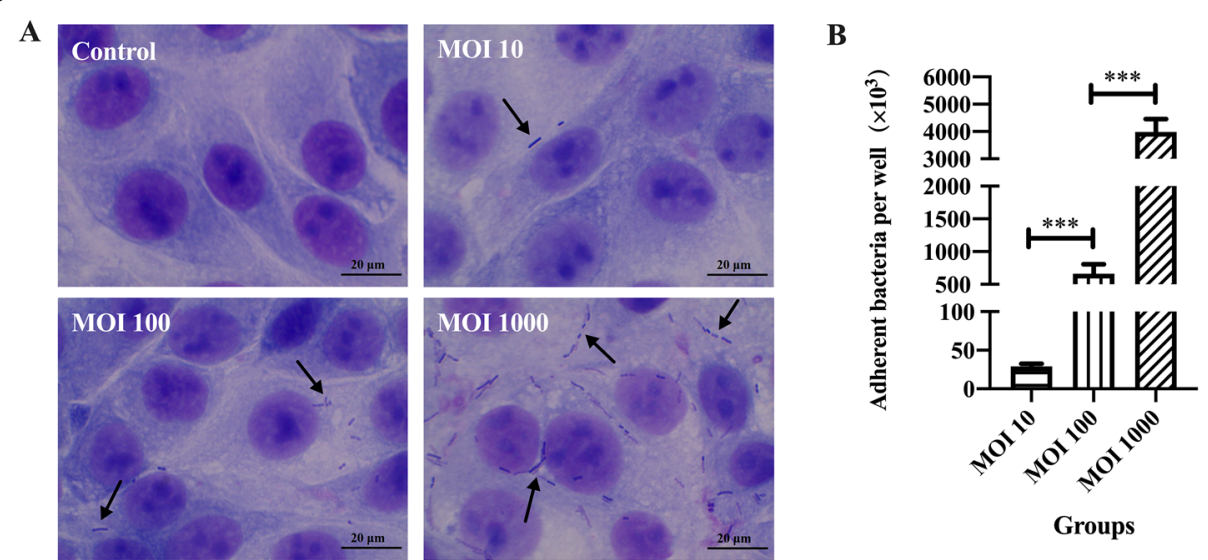

C

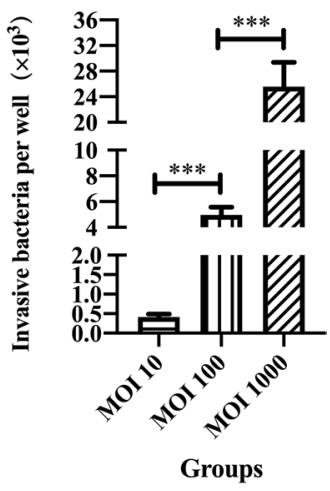

D

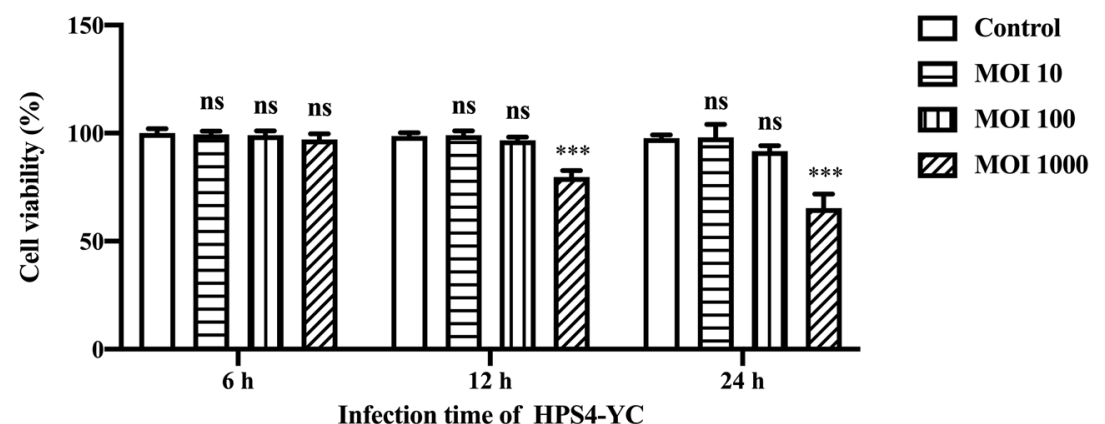

Figure 1 HPS4-YC infection in STEC. A Giemsa staining of HPS4-YC infecting STEC (100x). STEC were uninfected or infected with HPS4-YC at an $\mathrm{MOI}$ of 10, 100 or 1000 for $2 \mathrm{~h}$. The black arrows point to the bacteria present. Scale bar, $20 \mu \mathrm{m}$. B, C Adherence and invasion assays. STEC were infected with HPS4-YC at different MOI for $2 \mathrm{~h}$. The number of adherent and invasive bacteria per well was counted. D Cell viability of STEC were assessed by CCK-8. The results represent the means \pm SD of three independent experiments. Significant differences in B and C were analyzed using Student $t$ test. Significant differences in D were analyzed using one-way ANOVA. ns: not significant; ${ }^{* * *} P<0.001$

\section{HPS4-YC infection increased permeability of the tracheal epithelial barrier, allowing more rapid translocation of bacteria across epithelial monolayers}

To evaluate the influence of HPS4-YC infection on the paracellular permeability of STEC, an in vivo tracheal epithelial barrier model was established (Figure 2A). The TEER value is an indicator for assessing the integrity of the cell barrier [22]. The stabilization of TEER indicates the success of the construction (Figure 2B). Compared with the control group, HPS4-YC infection significantly decreased the TEER at $8,12,18$ and $24 \mathrm{~h}$ after infection, and there was no significance at $4 \mathrm{~h}$ and $6 \mathrm{~h}$ post-infection of HPS4-YC (Figure 2C), indicating that HPS4-YC infection gradually reduced the TEER value.

Furthermore, we investigated the impact of HPS4-YC on the permeability of the tracheal epithelial barrier by measuring the concentration of FITC-dextran crossing the transwell chamber. Relative to the uninfected control group, the permeability of the tracheal epithelial barrier in the HPS4-YC infection group was significantly increased in a time-dependent manner, as shown in Figure 2D. The results above indicate that HPS4-YC infection induced increased permeability and destroyed the integrity of the tracheal epithelial barrier.

The number of HPS4-YC penetrating the epithelial barrier model was counted at different times post-infection. As shown in Figure 2E, HPS4-YC crossed the in vitro tracheal epithelial barrier constructed with STEC after incubation for $8 \mathrm{~h}$, and the number of penetrated bacteria increased sharply with increasing infection time. This result further confirmed that HPS4-YC induced the breakdown of the epithelial barrier and contributed to the translocation of the bacterial pathogen GPS4.

\section{HPS4-YC caused TJ disruption in STEC}

To explore the effect of HPS4-YC infection on the expression of TJ, STEC were infected with HPS4-YC for 6, 12, 18 and $24 \mathrm{~h}$. Cellular protein was collected, and total RNA were extracted, followed by assessment by Western blotting and qRT-PCR. Western blot analysis shows that 

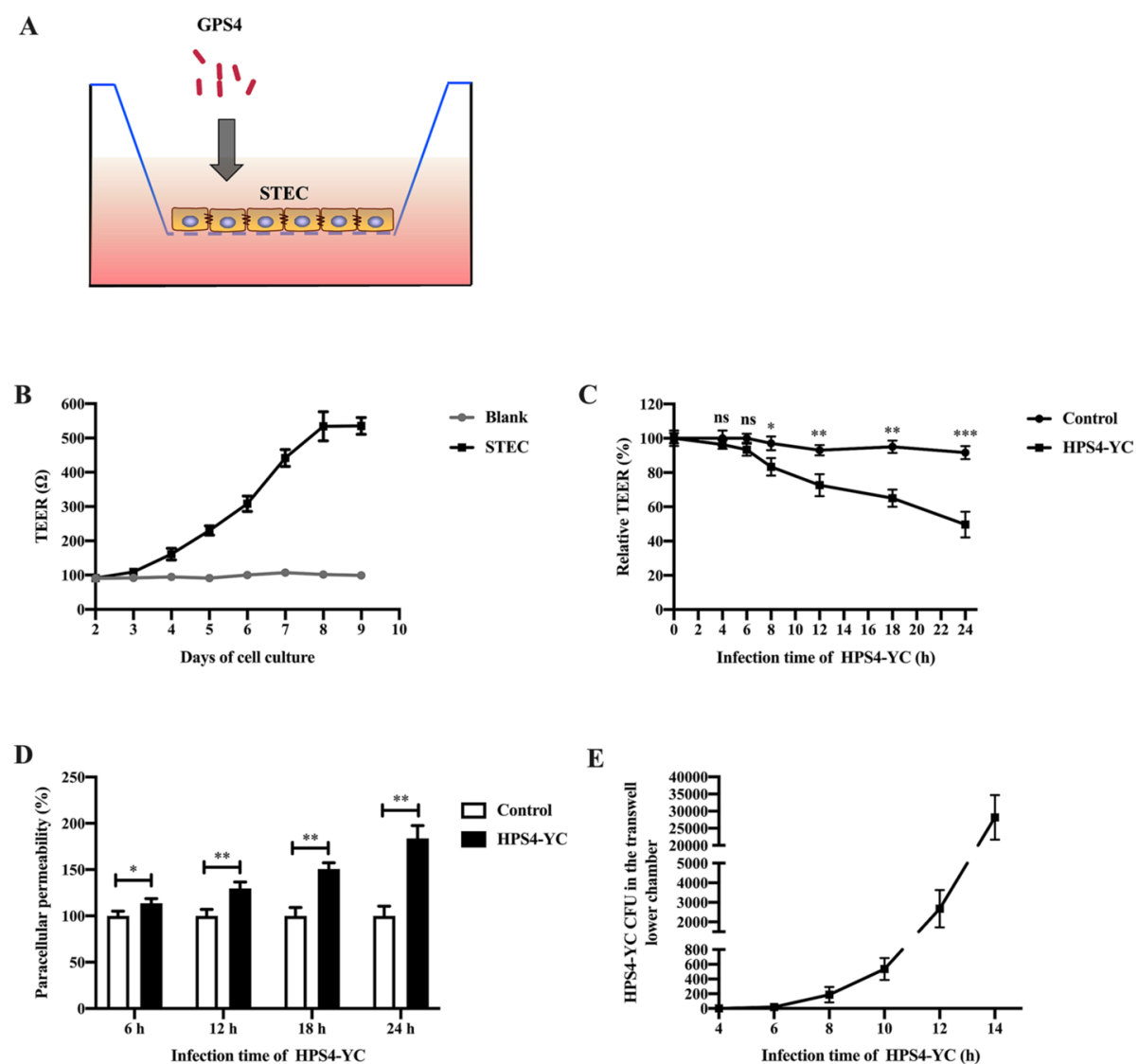

Figure 2 HPS4-YC infection increased tracheal epithelial barrier permeability. A In vitro model of tracheal epithelial barrier. STEC were cultured in a transwell, GPS4 was added to the upper chamber. B Construction of an in vitro tracheal epithelial barrier model. C HPS4-YC infection decreased the TEER of the epithelial barrier. STEC monolayers were uninfected or infected with HPS4-YC for different times, and TEER was measured. D Measurement of paracellular permeability. The epithelial barrier integrity was analyzed by monitoring FITC-conjugated dextran crossing the transwell chamber. Paracellular permeability is shown relative to the uninfected permeability. E CFU of HPS4-YC across the epithelial barrier model were counted. The results are shown as the mean \pm SD of three separate experiments. Significant differences in $B$ and $C$ were determined using the Student $t$ test. ns: not significant; ${ }^{*}, P<0.05 ;{ }^{* *}, P<0.01 ;{ }^{* * *} P<0.001$.

the expression of the $\mathrm{TJ} \mathrm{ZO}-1$ and occludin decreased during HPS4-YC infection (Figure 3A). Similarly, qRTPCR results show that compared to the control group, HPS4-YC infection caused a significant downregulation in the mRNA levels of ZO-1 and occludin (Figure 3B). These results indicate that continuous HPS4-YC infection in STEC led to a reduction in ZO-1 and occludin.

The effect of HPS4-YC on TJ was further investigated by immunofluorescence staining of $\mathrm{ZO}-1$ and occludin. As shown in Figure 3C, HPS4-YC infection had a destructive effect on epithelial cell tight junctions at $12 \mathrm{~h}$ and $24 \mathrm{~h}$. Compared to the control STEC monolayers, the continuous tight junction structures of $\mathrm{ZO}-1$ and occludin in HPS4-YC-infected cells were destroyed and could hardly constitute cell-cell junctions, which indicate that the integrity of the TJ ZO-1 and occludin were disrupted after HPS4-YC infection.

\section{HPS4-YC induced upregulation of proinflammatory} cytokines through activation of MAPK and NF-KB signaling pathways

The production of inflammatory cytokines is one of the important factors that affects TJ expression [23]. Total RNA from uninfected and HPS4-YC-infected STEC was extracted to assess the expression of the cytokines IL- 6, IL- 8 and TNF- $\alpha$ by qRT-PCR. The expression levels of the cytokines IL- 6, IL- 8 and TNF- $\alpha$ in the infected group were significantly higher than those in the control group at $12 \mathrm{~h}$ and $24 \mathrm{~h}$ post-infection (Figure $4 \mathrm{~A}$ ). Notably, the expression of IL- 8 and TNF- $\alpha$ was upregulated hundreds of times at both $12 \mathrm{~h}$ and $24 \mathrm{~h}$ post-infection of HPS4-YC (Figure 4A). In addition, levels of cytokines IL-6, IL- 8 and TNF- $\alpha$ in culture supernatant of STEC were evaluated. The ELISA results revealed that cytokines in the infected group were 
A

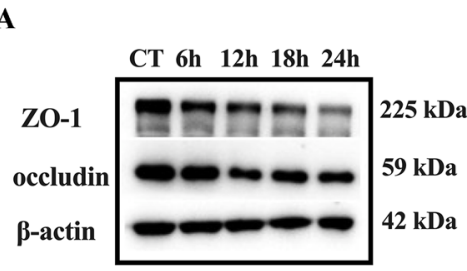

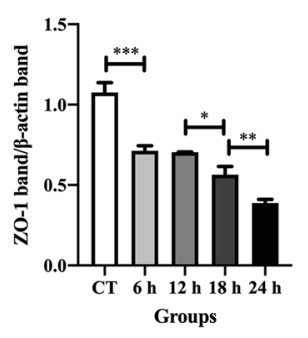

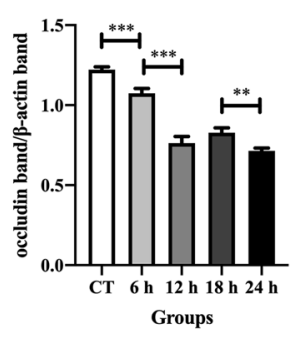

B
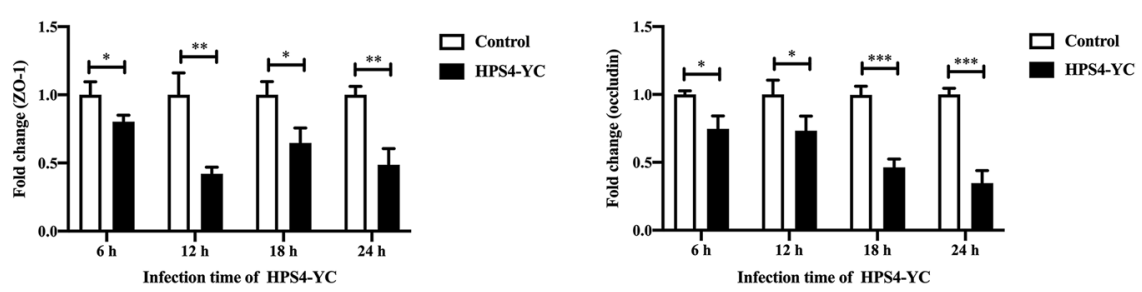

C
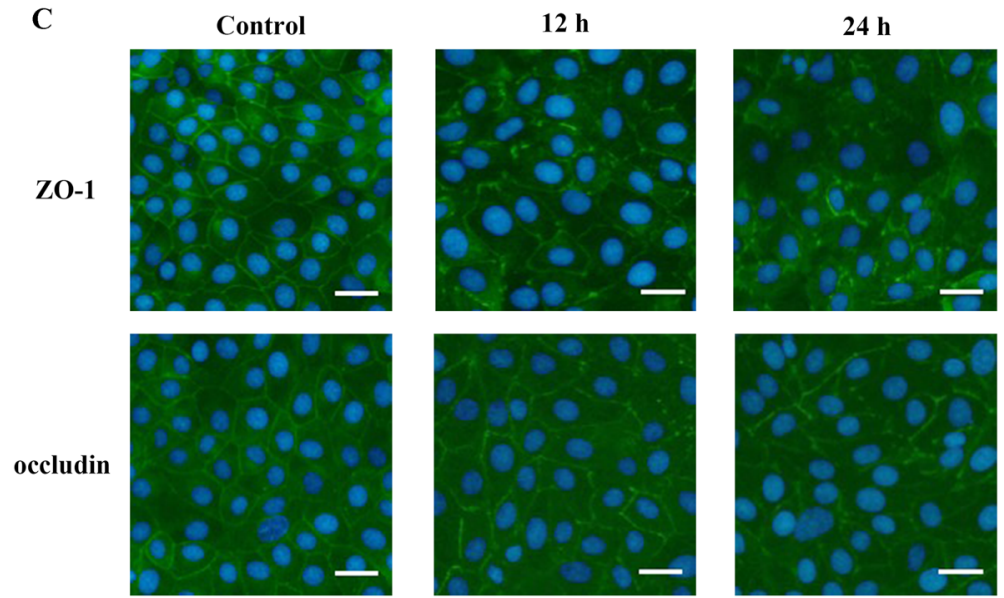

Figure 3 HPS4-YC infection induced disruption of TJ in STEC. STEC were infected with HPS4-YC for 6, 12, 18, and $24 \mathrm{~h}$. A Protein levels of ZO-1 and occludin were analyzed by Western blot. The protein band intensities were quantified by ImageJ software. HPS4-YC caused a time-dependent decrease in tight junction protein levels in STEC. CT, the control group. B mRNA levels of ZO-1 and occludin were analyzed with qRT-PCR. The results are shown as the mean \pm SD of triplicate independent experiments. Significant differences were analyzed using the Student $t$ test. ${ }^{*}, P<0.05$; ${ }^{* *}$, $P<0.01{ }^{* * *} P<0.001$. C Immunofluorescence staining of ZO-1 and occludin in STEC. The infection times of HPS4-YC were $12 \mathrm{~h}$ and $24 \mathrm{~h}$, then cells were fixed and the nucleus and TJ were stained (blue and green, respectively). HPS4-YC destroyed the integrity of TJ. Scale bar, $100 \mu \mathrm{m}$.

significantly higher than those in the control group at $12 \mathrm{~h}$ and $24 \mathrm{~h}$, which was consistent with the result of qRT-PCR (Figure 4B).

MAPK and NF-kB are well-known signaling pathways regulating the expression of proinflammatory cytokines [24]. To determine whether HPS4-YC infection could activate MAPK and NF- $\mathrm{KB}$ signaling pathways, phosphorylation of $\mathrm{p} 38$, ERK, and JNK in the MAPK pathway and phosphorylation of $\mathrm{p} 65$ and $\mathrm{I} \mathrm{kB} \alpha$ in the NF- $\mathrm{kB}$ pathway were assessed by Western blotting. At $12 \mathrm{~h}$ and $24 \mathrm{~h}$ post-infection with HPS4-YC, the expression levels of p-p38, p-ERK, p-JNK, p-p65 and p-IKB $\alpha$ were all significantly upregulated (Figures $4 \mathrm{C}, \mathrm{D}$ ). These results indicate that HPS4-YC infection activated both MAPK and NF- $\mathrm{KB}$ signaling pathways.

In addition, the mRNA levels of TNF- $\alpha$ were selected to identify the pathways signaling cytokine production. When MAPK or NF-kB signaling pathways were inhibited in HPS4-YC-infected STEC, TNF- $\alpha$ expression was significantly decreased (Figure 4E), indicating that cytokine production in HPS4-YC-infected STEC was regulated by both MAPK and NF- $\mathrm{KB}$ signaling pathways. 

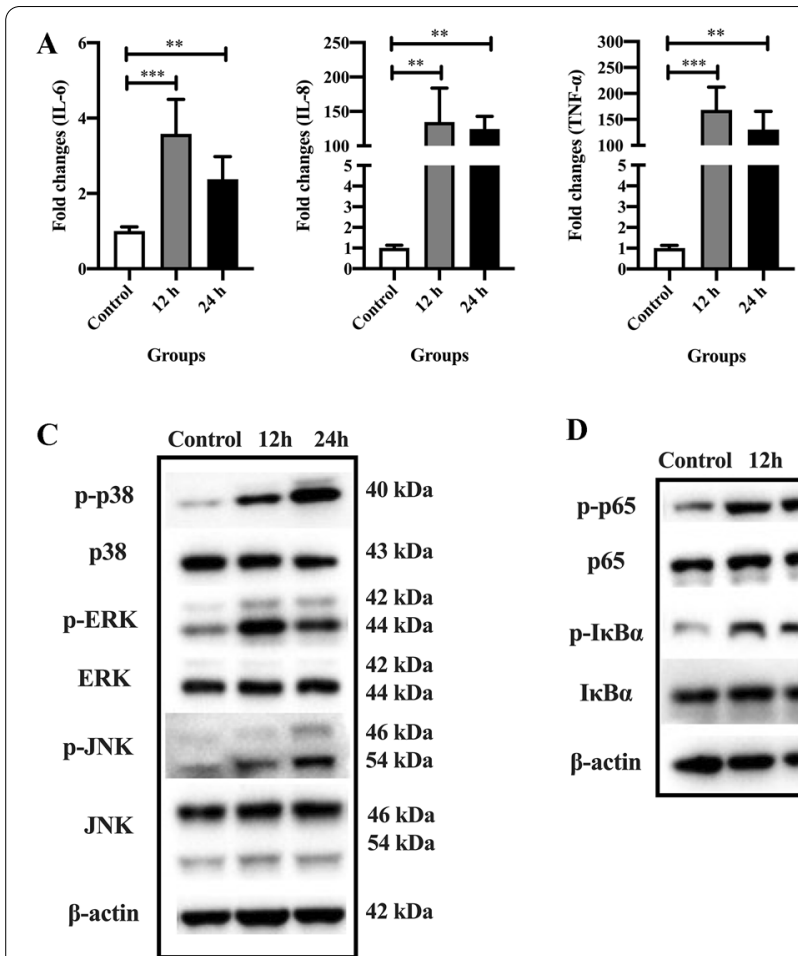
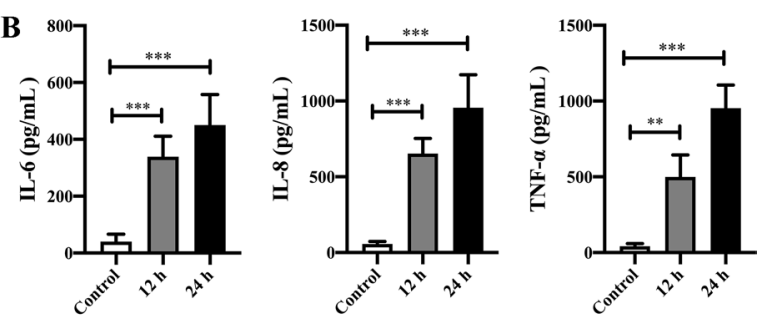

Groups

Groups

Groups

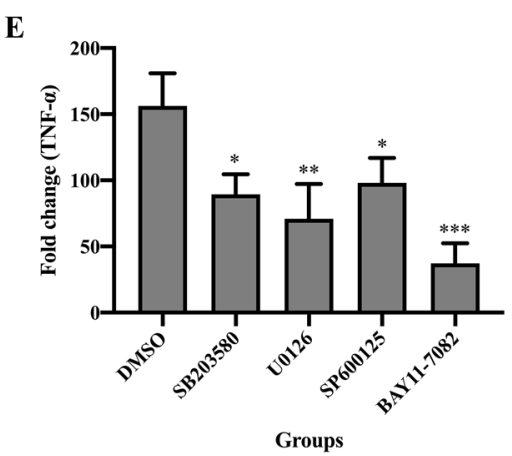

Figure 4 Proinflammatory cytokines were upregulated through activation of MAPK and NF-KB signaling pathways in HPS4-YC-infected STEC. A mRNA levels of cytokines IL-6, IL-8 and TNF-a were assessed through qRT-PCR assays. B Levels of the cytokines IL-6, IL-8 and TNF-a in culture supernatant of STEC were assessed by ELISA. C, D Activation of MAPK and NF-KB signaling pathways in STEC at $12 \mathrm{~h}$ and $24 \mathrm{~h}$ after HPS4-YC infection. The protein levels were determined by Western blot. E Expression of TNF-a was regulated by both MAPK and NF-KB signaling pathways. STEC were pretreated with DMSO or inhibitors for $1 \mathrm{~h}$ before HPS4-YC infection. The infection time of HPS4-YC was 12 h. SB203580, U0126, SP600125 and BAY11-7082 are inhibitors of p38, ERK, JNK and NF-KB, respectively. Data are shown as the mean \pm SD of three independent experiments. Significant differences were determined using one-way ANOVA. ${ }^{*}, P<0.05 ;{ }^{* *}, P<0.01 ;{ }^{* * *} P<0.001$.

\section{HPS4-YC-induced barrier damage was involved} in the secretion of proinflammatory cytokines

To investigate whether the damage to the tracheal epithelial barrier was a result of cytokines produced by epithelial cell infection with HPS4-YC, the supernatant of HPS4-YC-infected and mock-infected STEC was collected at $24 \mathrm{~h}$ post-infection. The supernatant was filtered to remove bacteria and then transferred to swine tracheal epithelial barrier model. Treatment with HPS4-YC supernatant resulted in a significant decline in TEER and increased the permeability of FITC-dextran (Figures 5A, B). Furthermore, recombinant human TNF- $\alpha$ was added to the apical chamber to determine its effect on the epithelial barrier. TNF- $\alpha$ treatment significantly decreased the TEER and increased the permeability of the epithelial barrier model (Figures $5 \mathrm{C}$, D). As determined by CCK-8, TNF- $\alpha$ had no significant cytotoxicity in STEC during the experiment (data not shown). These results suggest that cytokines present in the cell supernatant after HPS4-YC infection contributed to epithelial barrier damage.
HPS4-YC downregulated TJ in the lungs of piglets and caused a severe inflammatory response

Animal challenge experiments were performed to verify the disruption of $\mathrm{TJ}$ and the severe inflammatory response caused by HPS4-YC infection. The integrity of $\mathrm{TJ}$ in the lungs was observed through immunofluorescence assay; Western blotting and qRT-PCR were used to determine the expression of TJ. As shown in Figure 6A, ZO-1 and occludin in HPS4-YC-infected group were destroyed and discontinuous. In addition, the seronegative piglets may still carry pathogens, such as G. parasuis, but there is no TJ disruption in the control group, indicating that the disruption of TJ was caused by HPS4-YC infection. The protein levels were reduced compared with those in the control group, and the mRNA levels of ZO-1 and occludin in the lungs from the infected group were also lower than those from the control group (Figures 6B, C). These results suggest that HPS4-YC infection down-regulated the expression of TJ in the lungs, which was consistent with the results of our previous study. 


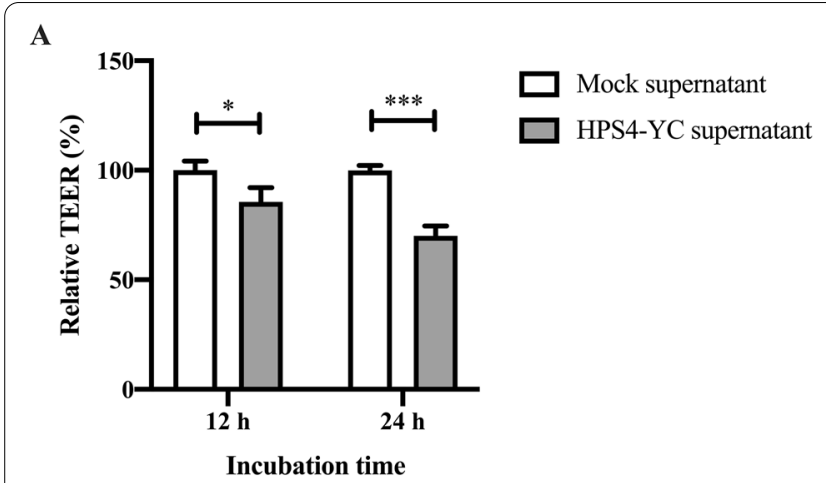

C

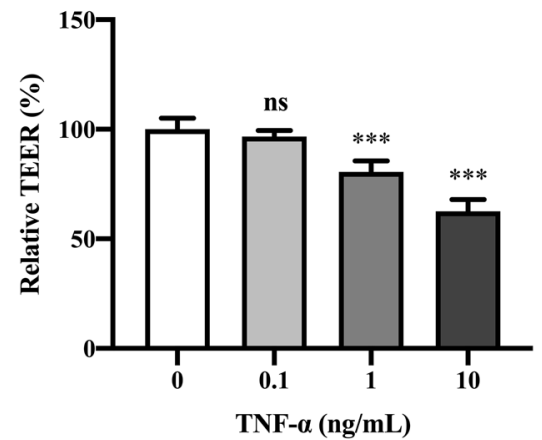

B

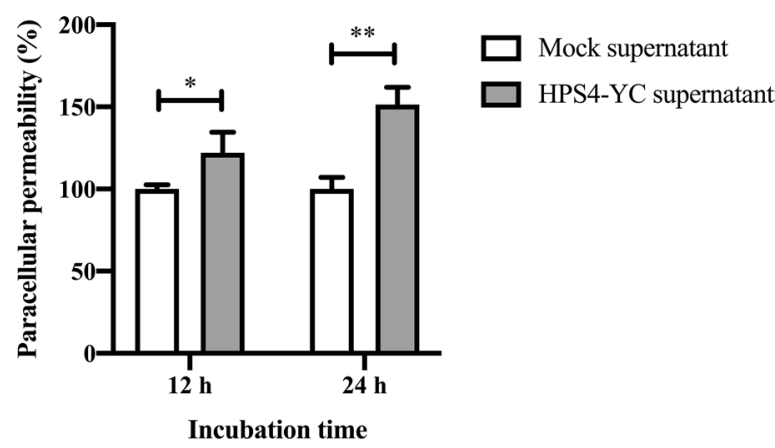

D

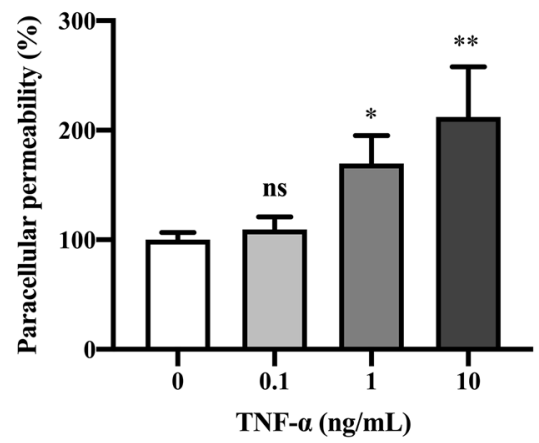

Figure 5 Effect of inflammatory cytokines on swine tracheal epithelial barrier damage. A, B Cytokines present in the supernatant decreased TEER and increased paracellular permeability respectively, promoting barrier damage. The supernatant of HPS4-YC-infected and mock-infected STEC was added to the upper chambers of transwells, and TEER and FITC-conjugated dextran crossing the transwell chamber were measured at $12 \mathrm{~h}$ and $24 \mathrm{~h}$. C, D TNF-a damaged the epithelial barrier integrity. Different concentrations of TNF-a were added to the medium in the apical compartment for $24 \mathrm{~h}$, and TEER and paracellular permeability were measured to determine their effect on epithelial barrier integrity. Data are shown as the mean \pm SD of triplicate assays. Significant differences in A and B were determined using Student $t$ test. Significant differences in $C$ and $D$ were determined using one-way ANOVA. ns: not significant; ${ }^{*}, P<0.05 ;{ }^{* *}, P<0.01 ;{ }^{* * *} P<0.001$.

In addition, $H \& E$ staining shows that the lungs exhibited alveolar wall thickening and inflammatory cell infiltration in the HPS4-YC-infected group (Figure 7A). Levels of cytokines IL-6, IL-8 and TNF- $\alpha$ in serum samples were measured at 3,5 and $7 \mathrm{dpi}$. The ELISA results revealed that cytokines in the infected group were significantly higher than those in the control group at $5 \mathrm{dpi}$ and 7 dpi (Figure 7B). HPS4-YC infection caused a severe inflammatory response in piglets.

\section{Discussion}

G. parasuis is a commensal bacterium in the upper respiratory tract of pigs and can invade and cause disease [4]. However, how G. parasuis penetrates the respiratory barrier and causes infection is not yet fully understood. Epithelial cells are the first line of defense against pathogenic microorganisms, either respiratory or intestinal pathogens. Pathogenic microorganisms have developed different strategies to impair the epithelial barrier, resulting in invasive infection and systemic disease $[25,26]$. TJ are located at the border of epithelial cells and are critical for maintaining epithelial barrier function [27]. Influenza A virus downregulates the expression of intercellular junction proteins E-cadherin, occludin and ZO-1, resulting in alveolar epithelial barrier damage [28]. The virulence factor pneumolysin of Streptococcus pneumoniae reduces the expression of ZO-1 in lung epithelial cells and causes a breakdown of the epithelial barrier [29]. Here, we demonstrate that HPS4-YC downregulated the expression of TJ ZO-1 and occludin, breaking the integrity of the swine tracheal epithelial barrier and enabling rapid bacterial translocation.

The assembly, disassembly and maintenance of TJ are influenced by various physiological and pathological stimuli. Microbial agents can modulate signaling pathways that participate in the organization of TJ, such as the MLCK and MAPK pathways, leading to changes in gene expression encoding $\mathrm{TJ}$ or cellular redistribution of $\mathrm{TJ}[26,30]$. In addition, altered epithelial TJ have been reported to result from proinflammatory cytokine 


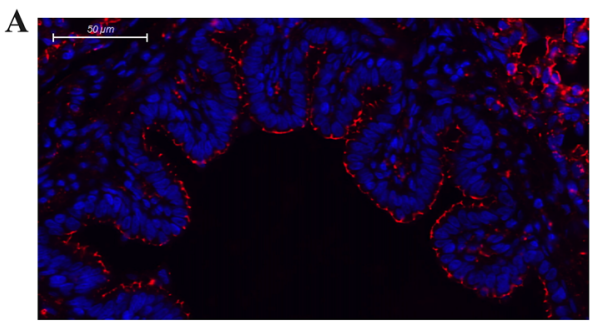

ZO-1 (Control)

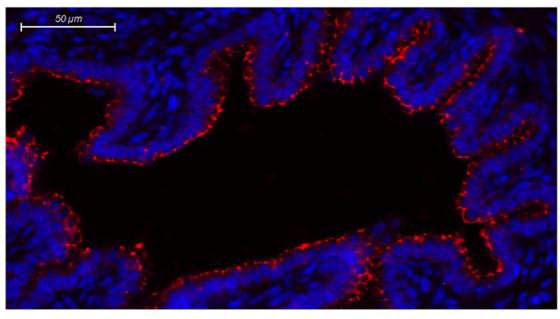

occludin (Control)

B

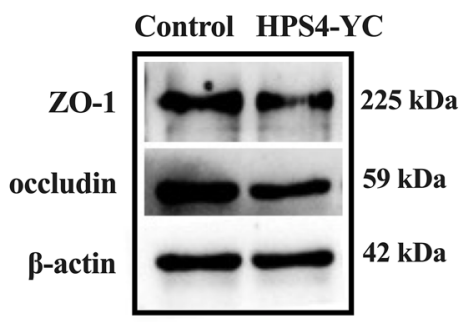

C

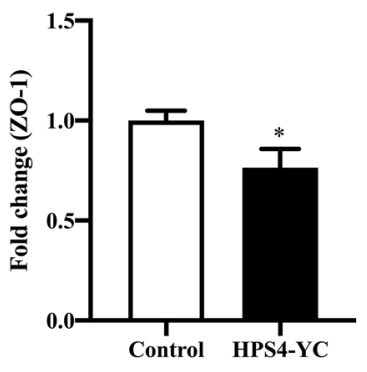

Groups

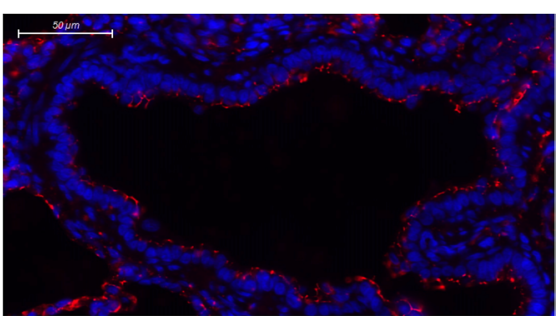

ZO-1 (HPS4-YC)

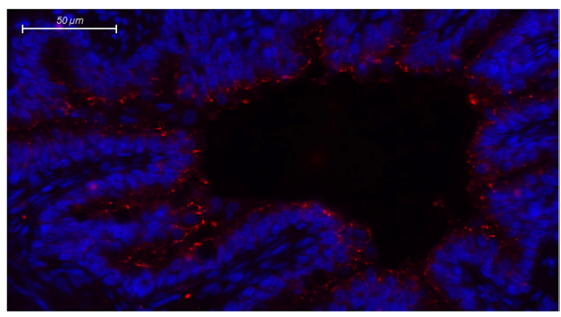

occludin (HPS4-YC)
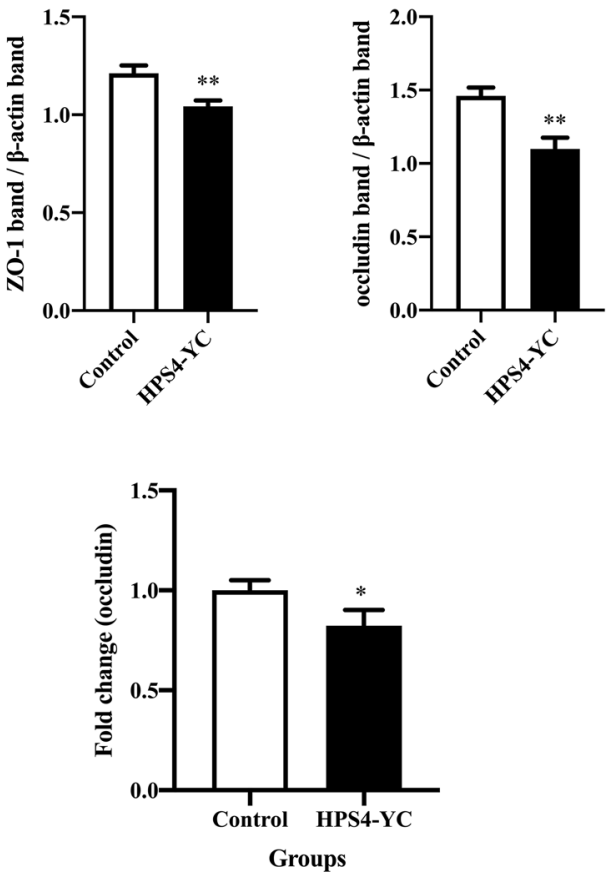

Figure 6 HPS4-YC downregulated tight junction protein levels in the lungs of piglets. A Immunofluorescence staining of ZO-1 and occludin in the lungs. Blue, the nucleus. Red, ZO-1 or occludin. Scale bar, $50 \mu \mathrm{m}$. B Protein levels of ZO-1 and occludin in the lungs were analyzed by Western blot. HPS4-YC decreased the expression of ZO-1 and occludin. C mRNA levels of ZO-1 and occludin in the lungs were analyzed with qRT-PCR. The results were in accordance with cell experiments. Data are shown as the mean \pm SD of three independent experiments. Significant differences were determined using the Student $t$ test. ${ }^{*}, P<0.05 ;{ }^{*}, P<0.01$.

production, which can also subsequently activate regulatory pathways linked to TJ [26]. Here, we show that HPS4-YC induced significant upregulation of IL-6, IL-8 and TNF- $\alpha$. Inflammation is a double-edged sword; although it is necessary for relieving of infection, an excessive inflammatory response can cause tissue damage and promote infection [31]. Staphylococcus aureus triggers the secretion of IL-6 and IL-8, leading to human nasal epithelial barrier dysfunction [7]. Klebsiella pneumoniae induces IFN- $\gamma$, causing a decrease in airway 

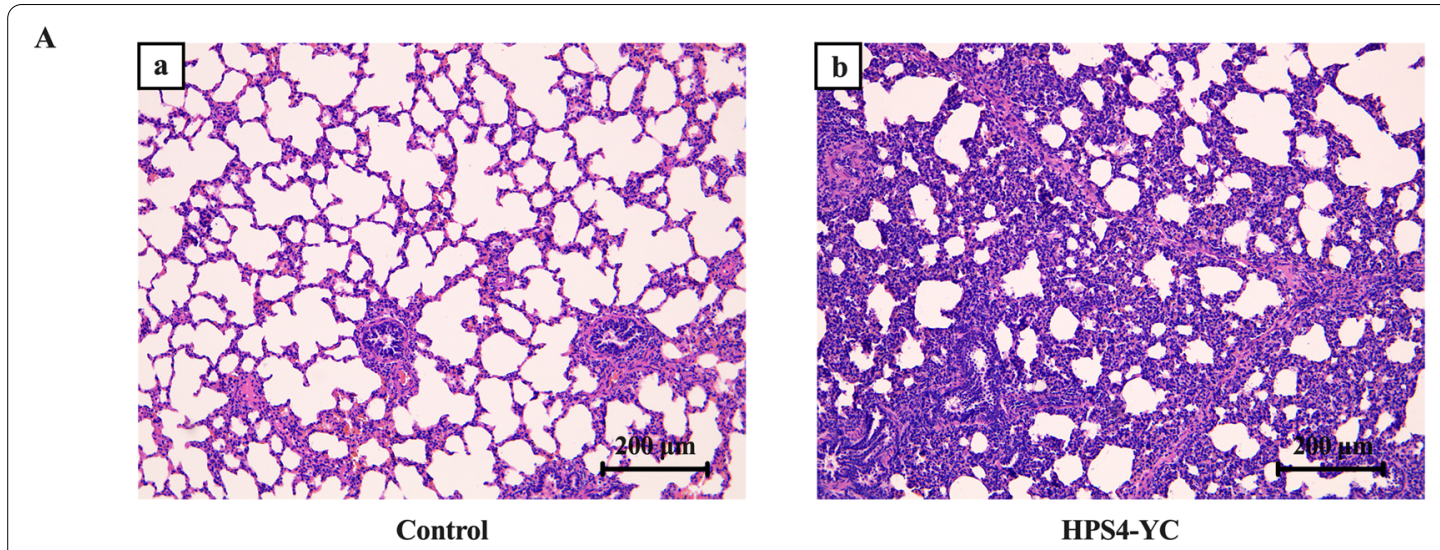

B
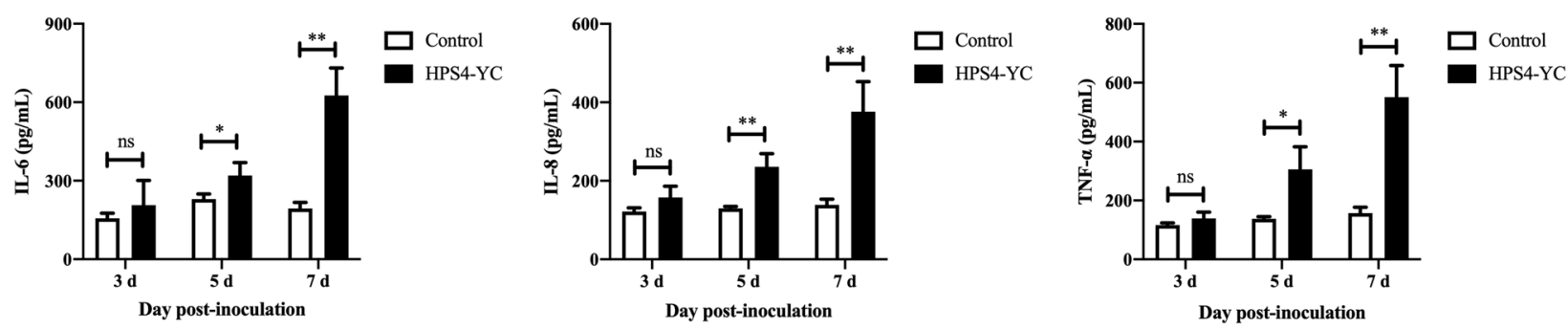

Figure 7 Histopathological examination of the lungs and detection of proinflammatory cytokines in serum. A Representative histopathological images of piglets mock-infected or infected with HPS4-YC. Scale bar, $200 \mu \mathrm{m}$. B Levels of the proinflammatory cytokines IL-6, IL-8 and TNF- $a$ in serum samples were assessed by ELISA. Data are presented as mean \pm SD of three independent experiments. Significant differences were determined using the Student $t$ test. ns not significant; ${ }^{*}, P<0.05 ;{ }^{* *}, P<0.01$.

epithelial barrier integrity [32]. Consistent with these observations, TNF- $\alpha$ production in HPS4-YC-infected STEC increased paracellular permeability and contributed to epithelial barrier disruption. However, in contrast to the above studies, Sajjan et al. reported that rhinovirus-induced disruption of airway epithelial barrier function is independent of proinflammatory cytokines [33]; a strong proinflammatory response induced by influenza virus is not responsible for alveolar epithelial barrier damage [10]. The destructive effect of inflammatory cytokines on the epithelial barrier is one of the ways that facilitates microbial pathogen infection, and this effect might be related to the type of epithelial cells, the levels of cytokines and the presence of anti-inflammatory cytokines such as IL-10 [15].

Additionally, the signaling pathways that regulate cytokine production in STEC were investigated. Our data show that HPS4-YC induced the production of TNF- $\alpha$ through activation of both the MAPK and NF-kB signaling pathways, which was consistent with previous studies about G. parasuis [34, 35]. Previous studies have reported that TNF- $\alpha$ induce increased intestinal epithelial or endothelial barrier permeability through NF- $\mathrm{KB}$ activation [36, 37]. Accumulating evidence suggests that the
MAPK pathway can regulate the expression of TJ in different types of epithelial cells and the permeability of the epithelial barrier [38]. For example, activation of ERK/ MAPK leads to decreased ZO-1 and occludin expression in H1N1 influenza virus-infected A549 cells [28]. Clarke et al. reported that Streptococcus pneumoniae and Haemophilus influenzae downregulate the expression of $\mathrm{TJ}$ in respiratory epithelial cells and destroy the integrity of the epithelial barrier through activation of the p38/MAPK pathway [11]. These observations suggest that in addition to the production of cytokines, the MAPK pathway may directly regulate TJ expression during HPS4-YC infection. There are several unsolved issues in our study, such as the interactions between $G$. parasuis effectors and surface receptors that lead to activation of MAPK and NF- $\mathrm{K} B$ signaling pathways, which have not been investigated. Whether and how MAPK and NF- $\kappa B$ activation in HPS4-YC-infected STEC results in a reduction of TJ require further research.

In summary, we have shown that G. parasuis infection downregulated $\mathrm{TJ}$ and disrupted epithelial barrier integrity, favoring bacterial translocation. The disruption of $\mathrm{T}$ ) and epithelial damage were related to the release of proinflammatory cytokines, and the expression of cytokines 
depended on the activation of MAPK and NF-kB. These findings will help clarify the pathogenic mechanism of $G$. parasuis, and contribute to better control strategies of swine Glässer disease.

\begin{abstract}
Abbreviations
G. parasuis: Glaesserella parasuis; GPS4: Glaesserella parasuis Serotype 4; MOI: multiplicity of infection; TJ: tight junction proteins; STEC: swine tracheal epithelial cells; TEER: transepithelial electrical resistance; MAPK: mitogen-activated protein kinases; NF-kB: nuclear factor-kappa B; dpi: day post-inoculation; SDS-PAGE: sodium dodecyl sulfate-polyacrylamide gel electrophoresis; PVDF: polyvinylidene fluoride; GRT-PCR: quantitative reverse transcription PCR; IL: interferon; TNF: tumor necrosis factor; PCV2: porcine circovirus type 2; PRRSV: porcine reproductive and respiratory syndrome virus.
\end{abstract}

\section{Acknowledgements}

We thank Mrs. Hong Zhou for help in reagent ordering, and thank Mr. Pengyun Zhang, Ms. Bing Wu and Ms. Ting Zhu for helping with the animal challenge experiments.

\section{Authors' contributions}

QW and XC performed most of the experiments in the manuscript and wrote the article. ML, QL and MZ analyzed the data. HL corrected the manuscript. HF provided expertise and designed the study. All authors read and approved the final manuscript.

\section{Funding}

This study was supported by the National Key Research and Development Program of China (2017YFD0500203), the Jiangsu Agricultural Science and Technology Innovation Fund (CX(19)2020), the Research Fund for Introducing and Stabilizing Talents of Anhui Agricultural University (rc392012), and the Priority Academic Program Development of Jiangsu Higher Education Institutions (PAPD).

\section{Declarations}

\section{Competing interests}

The authors declare that they have no competing interests.

\section{Author details}

${ }^{1}$ Anhui Province Key Laboratory of Veterinary Pathobiology and Disease Control, College of Animal Science and Technology, Anhui Agricultural University, Hefei 230036, China. ${ }^{2}$ MOE Joint International Research Laboratory of Animal Health and Food Safety, College of Veterinary Medicine, Nanjing Agricultural University, Nanjing 210095, China. ${ }^{3}$ Jiangsu Co-Innovation Center for the Prevention and Control of Important Animal Infectious Diseases and Zoonoses, Yangzhou University, Yangzhou 225009, China.

Received: 8 July 2021 Accepted: 30 August 2021

Published online: 21 October 2021

\section{References}

1. Hau SJ, Eberle KC, Brockmeier SL (2021) Importance of strain selection in the generation of heterologous immunity to Glaesserella (Haemophilus) parasuis. Vet Immunol Immunopathol 234:110205

2. Costa-Hurtado M, García-Rodríguez L, López-Serrano S, Aragón V (2019) Haemophilus parasuis VtaA2 is involved in adhesion to extracellular proteins. Vet Res 50:69

3. Jia A, Zhou R, Fan H, Yang K, Zhang J, Xu Y, Wang G, Liao M (2017) Development of serotype-specific PCR assays for typing of Haemophilus parasuis isolates circulating in southern China. J Clin Microbiol 55:3249-3257

4. Macedo N, Rovira A, Torremorell M (2015) Haemophilus parasuis: infection, immunity and enrofloxacin. Vet Res 46:128
5. Costa-Hurtado M, Barba-Vidal E, Maldonado J, Aragón V (2020) Update on Glasser's disease: how to control the disease under restrictive use of antimicrobials. Vet Microbiol 242:108595

6. Rezaee F, Georas SN (2014) Breaking barriers new insights into airway epithelial barrier function in health and disease. Am J Respir Cell Mol Biol 50:857-869

7. Martens K, Seys SF, Alpizar YA, Schrijvers R, Bullens DMA, Breynaert C, Lebeer S, Steelant B (2021) Staphylococcus aureus enterotoxin B disrupts nasal epithelial barrier integrity. Clin Exp Allergy 51:87-98

8. Georas SN, Rezaee F (2014) Epithelial barrier function: At the front line of asthma immunology and allergic airway inflammation. J Allergy Clin Immunol 134:509-520

9. Drolia R, Bhunia AK (2019) Crossing the intestinal barrier via Listeria adhesion protein and internalin A. Trends Microbiol 27:408-425

10. Short KR, Kasper J, van der Aa S, Andeweg AC, Zaaraoui-Boutahar F, Goeijenbier M, Richard M, Herold S, Becker C, Scott DP, Limpens RWAL, Koster AJ, Barcena M, Fouchier RAM, Kirkpatrick CJ, Kuiken T (2016) Influenza virus damages the alveolar barrier by disrupting epithelial cell tight junctions. Eur Respir J 47:954-966

11. Clarke TB, Francella N, Huegel A, Weiser JN (2011) Invasive bacterial pathogens exploit TLR-mediated downregulation of tight junction components to facilitate translocation across the epithelium. Cell Host Microbe 9:404-414

12. Wang H, Zhang Z, Xie X, Liu B, Wei Y, Gan Y, Yuan T, Ni B, Wang J, Zhang L, Xiong Q, Shao G, Feng Z (2020) Paracellular pathway-mediated Mycoplasma hyopneumoniae migration across porcine airway epithelial barrier under air-liquid interface conditions. Infect Immun 88:e00470-e520

13. Bercier P, Grenier D (2019) TNF-alpha disrupts the integrity of the porcine respiratory epithelial barrier. Res Vet Sci 124:13-17

14. Wang H, Wei W, Cao Q, Xu M, Chen Q, Lv Y, Tan C, Dai M, Xu X, Chen H, Wang $X$ (2021) Sialylated lipooligosaccharide contributes to Glaesserella parasuis penetration of porcine respiratory epithelial barrier. ACS Infect Dis 7:661-671

15. Capaldo CT, Nusrat A (2009) Cytokine regulation of tight junctions. Biochim Biophys Acta 1788:864-871

16. Petecchia L, Sabatini F, Usai C, Caci E, Varesio L, Rossi GA (2012) Cytokines induce tight junction disassembly in airway cells via an EGFR-dependent MAPK/ERK1/2-pathway. Lab Invest 92:1140-1148

17. Luo XR, Chang XJ, Zhou H, Lin HX, Fan HJ (2021) Glaesserella parasuis induces inflammatory response in 3D4/21 cells through activation of NLRP3 inflammasome signaling pathway via ROS. Vet Microbiol 256:109057

18. Wang Q, Zhou H, Lin H, Ma Z, Fan H (2020) Porcine circovirus type 2 exploits JNK-mediated disruption of tight junctions to facilitate Streptococcus suis translocation across the tracheal epithelium. Vet Res 51:31

19. Livak KJ, Schmittgen TD (2001) Analysis of relative gene expression data using real-time quantitative PCR and the 2(-Delta Delta C(T)) Method. Methods 25:402-408

20. Wang Q, Zhou H, Hao Q, Li M, Liu J, Fan H (2020) Coinfection with porcine circovirus type 2 and Streptococcus suis serotype 2 enhances pathogenicity by dysregulation of the immune responses in piglets. Vet Microbiol 243:108653

21. Eberle KC, Hau SJ, Luan SL, Weinert LA, Stasko JA, Wang J, Peters SE, Langford PR, Rycroft AN, Wren BW, Maskell DJ, Tucker AW, Brockmeier SL (2020) Generation and evaluation of a Glaesserella (Haemophilus) parasuis capsular mutant. Infect Immun 88:e00879-e919

22. Srinivasan B, Kolli AR, Esch MB, Abaci HE, Shuler ML, Hickman JJ (2015) TEER measurement techniques for in vitro barrier model systems. J Lab Autom 20:107-126

23. Suzuki T (2013) Regulation of intestinal epithelial permeability by tight junctions. Cell Mol Life Sci 70:631-659

24. Shi JH, Sun SC (2018) Tumor necrosis factor receptor-associated factor regulation of nuclear factor kappaB and mitogen-activated protein kinase pathways. Front Immunol 9:1849

25. Pawlowska B, Sobieszczanska BM (2017) Intestinal epithelial barrier: the target for pathogenic Escherichia coli. Adv Clin Exp Med 26:1437-1445

26. Paradis T, Begue H, Basmaciyan L, Dalle F, Bon F (2021) Tight junctions as a key for pathogens invasion in intestinal epithelial cells. Int J Mol Sci 22:2506

27. Otani T, Furuse M (2020) Tight junction structure and function revisited. Trends Cell Biol 30:805-817 
28. Ruan T, Sun J, Liu W, Prinz RA, Peng D, Liu X, Xu X (2020) H1N1 influenza virus cross-activates Gli1 to disrupt the intercellular junctions of alveolar epithelial cells. Cell Rep 31:107801

29. Jacques LC, Panagiotou S, Baltazar M, Senghore M, Khandaker S, Xu R, Bricio-Moreno L, Yang M, Dowson CG, Everett DB, Neill DR, Kadioglu A (2020) Increased pathogenicity of pneumococcal serotype 1 is driven by rapid autolysis and release of pneumolysin. Nat Commun 11:1892

30. Drolia R, Tenguria S, Durkes AC, Turner JR, Bhunia AK (2018) Listeria adhesion protein induces intestinal epithelial barrier dysfunction for bacterial translocation. Cell Host Microb 23:470-484

31. Schmit T, Ghosh S, Mathur RK, Barnhardt T, Ambigapathy G, Wu M, Combs C, Khan MN (2020) IL-6 deficiency exacerbates allergic asthma and abrogates the protective effect of allergic inflammation against Streptococcus pneumoniae pathogenesis. J Immunol 205:469-479

32. Ahn D, Wickersham M, Riquelme S, Prince A (2019) The effects of IFNlambda on epithelial barrier function contribute to Klebsiella pneumoniae ST258 pneumonia. Am J Respir Cell Mol Biol 60:158-166

33. Sajjan U, Wang Q, Zhao Y, Gruenert DC, Hershenson MB (2008) Rhinovirus disrupts the barrier function of polarized airway epithelial cells. Am J Respir Crit Care Med 178:1271-1281

34. Zeng Z, Chen X, Yue H, He H, Ren Y, Tang C, Zhang B (2018) The effect of $\mathrm{rfaD}$ and $\mathrm{rfaF}$ of Haemophilus parasuis on lipooligosaccharide induced inflammation by NF-kappaB/MAPKs signaling in porcine alveolar macrophages. J Vet Med Sci 80:842-845
35. Chen Y, Liu T, Langford P, Hua K, Zhou S, Zhai Y, Xiao H, Luo R, Bi D, Jin H, Zhou R (2015) Haemophilus parasuis induces activation of NF-kappaB and MAP kinase signaling pathways mediated by toll-like receptors. Mol Immunol 65:360-366

36. Ma TY, Iwamoto GK, Hoa NT, Akotia V, Pedram A, Boivin MA, Said HM (2004) TNF-alpha-induced increase in intestinal epithelial tight junction permeability requires NF-kappa B activation. Am J Physiol Gastrointest Liver Physiol 286:G367-376

37. Zhong J, Yu R, Zhou Q, Liu P, Liu Z, Bian Y (2021) Naringenin prevents TNFalpha-induced gut-vascular barrier disruption associated with inhibiting the NF-kappaB-mediated MLCK/p-MLC and NLRP3 pathways. Food Funct 12:2715-2725

38. Xiong W, Huang J, Li X, Zhang Z, Jin M, Wang J, Xu Y, Wang Z (2020) Icariin and its phosphorylated derivatives alleviate intestinal epithelial barrier disruption caused by enterotoxigenic Escherichia coli through modulate p38 MAPK in vivo and in vitro. FASEB J 34:1783-1801

\section{Publisher's Note}

Springer Nature remains neutral with regard to jurisdictional claims in published maps and institutional affiliations.
Ready to submit your research? Choose BMC and benefit from:

- fast, convenient online submission

- thorough peer review by experienced researchers in your field

- rapid publication on acceptance

- support for research data, including large and complex data types

- gold Open Access which fosters wider collaboration and increased citations

- maximum visibility for your research: over $100 \mathrm{M}$ website views per year

At BMC, research is always in progress.

Learn more biomedcentral.com/submissions 